\title{
DETEKSI PERKEMBANGAN ANAK USIA 3 BULAN - 72 BULAN MENGGUNAKAN KUESIONER PRA SKRINING PERKEMBANGAN (KPSP)
}

\author{
Christina Entoh, Fransisca Noya, Kadar Ramadhan* \\ Juruan Kebidanan Poltekkes Kemenkes Palu \\ *Email Korespondensi: kadarlaure@gmail.com
}

\begin{abstract}
More than a third of children in the world experience growth and development disorders both physically and mentally, and an estimated 5 to $10 \%$ of the child population has developmental delays. Child development problems such as motor delays, language, behavior, autism, hyperactivity, have increased in recent years, the occurrence in the United States ranges from 12-16.6\%, Thailand 24\%, Argentina $22.5 \%$, and in Indonesia between $13 \%-18 \%$. Approximately $16 \%$ of children under five years old (toddlers). Indonesia experiences neurological and brain development disorders ranging from mild to severe. The purpose of this study is to increase the motivation of toddlers to carry out routine child development checks, increase the participation of toddlers to carry out child development checks using KPSP, early detection of growth, and developmental disorders. The method used in this community service is varied lectures. The speakers did a demonstration to mothers who have children of $3-72$ months. Each mother gave information about their child's age and early detection of growth and development using KPSP according to the age child age. Results: Out of 140 children aged $3-72$ months who were detected developmentally using the Pre Development Screening Questionnaire (KPSP), there were 134 children $(95.7 \%)$ with normal results and 6 people $(4.3 \%)$ with doubtful results and none $(0 \%)$ who experienced deviance. Conclusion: The 6 children with doubtful screening results, after 2 weeks of screening, obtained $100 \%$ normal developmental results. Suggestion: Early detection can find growth disorders and child development, therefore, an intervention can be done as early as possible.
\end{abstract}

Keywords: Growth detection, KPSP

\begin{abstract}
ABSTRAK
Lebih dari sepertiga anak di dunia mengalami gangguan pertumbuhan dan perkembangan baik fisik maupun mental dan diperkirakan 5 sampai $10 \%$ dari populasi anak memiliki keterlambatan perkembangan. Masalah perkembangan anak seperti keterlambatan motorik, berbahasa, perilaku, autisme, hiperaktif, dalam beberapa tahun terakhir ini semakin meningkat, angka kejadian di Amerika serikat berkisar $12-16,6 \%$, Thailand $24 \%$, Argentina $22,5 \%$ dan di Indonesia antara $13 \%-18 \%$. Sekitar $16 \%$ dari anak usia dibawah lima tahun (balita) Indonesia mengalami gangguan perkembangan saraf dan otak mulai ringan sampai berat. Metode yang digunakan dalam pengabdian masyarakat ini adalah ceramah bervariasi, Demonstrasi dilakukan oleh pemateri penyuluhan dihadapan ibu yang memiliki anak 3 bulan - 72 bulan. Masing - masing ibu ditanyakan usia anaknya dan melakukan deteksi dini tumbuh kembang menggunakan KPSP sesuai usia anak. Hasil: dari 140 anak umur $3-72$ bulan yang dilakukan deteksi perkembangan menggunakan Kuesioner Pra Skrining Perkembangan (KPSP) terdapat 134 anak $(95,7 \%)$ dengan hasil yang sesuai dan 6 orang $(4,3 \%)$ dengan hasil meragukan dan tidak ada (0\%) yang mengalami penyimpangan. Kesimpulan : Dari 6 anak dengan hasil skrining meragukan, setelah 2 minggu kemudian dilakukan skrining, memperoleh hasil perkembangan $100 \%$ sesuai. Saran: Deteksi dini perkembangan dapat menemukan gangguan pertumbuhan dan perkembangan anak sehingga dapat dilakukan intervensi sedini mungkin
\end{abstract}

Kata Kunci: Deteksi perkembangan, KPSP 


\section{PENDAHULUAN}

Anak merupakan generasi penerus bangsa serta menjadi tumpuan dan harapan orangtua. Bangsa memerlukan anak yang berkualitas untuk mencapai masa depan yang baik, oleh karena itu penting memperhatikan proses pertumbuhan dan perkembangan anak. Masa balita adalah masa lima tahun pertama yang sangat penting dalam proses tumbuh kembang anak, masa ini adalah landasan bagi pertumbuhan dan perkembangan selanjutnya. Masa balita disebut juga golden periode, sedangkan masa batita disebut masa critical periode merupakan masa pertumbuhan dan perkembangan yang paling pesat pada otak manusia. Pada masa ini otak bersifat plastis dibandingkan dengan orang dewasa sehingga balita sangat terbuka dan peka dalam menerima berbagai macam pembelajaran dan pengkayaan baik bersifat positif maupun negatif. Tumbuh kembang balita akan optimal jika lingkungan memberikan dukungan yang positif atau sebaliknya (Bustan, 2007).

Pemantauan tumbuh kembang anak secara komprehensif dan berkualitas yang dilakukan melalui kegiatan stimulasi/rangsangan, deteksi dan intervensi dini penyimpangan tumbuh kembang balita dilakukan pada "masa kritis" ini (Sutiari \& Wulandari, 2011). Lebih dari sepertiga anak di dunia mengalami gangguan pertumbuhan dan perkembangan baik fisik maupun mental dan diperkirakan 5 sampai 10\% dari populasi anak memiliki keterlambatan perkembangan (Kementerian Kesehatan R.I, 2013b).

Masalah perkembangan anak seperti keterlambatan motorik, berbahasa, perilaku, autisme, hiperaktif, dalam beberapa tahun terakhir ini semakin meningkat, angka kejadian di Amerika serikat berkisar 12-16,6\%, Thailand 24\%, Argentina 22,5\% dan di Indonesia antara 13\%-18\% (Pujiawati D, 2013). Sekitar 16\% dari anak usia dibawah lima tahun (balita) Indonesia mengalami gangguan perkembangan saraf dan otak mulai ringan sampai berat (Uswaton \& Wulandari, 2011).

Di Indonesia diperkirakan 16\% balita mengalami gangguan perkembangan, yakni perkembangan motorik halus dan kasar, gangguan pendengaran dan kecerdasan yang kurang. Prevalensi gangguan perkembangan paling tinggi terjadi pada gangguan bahasa $(13,8 \%)$, dan diikuti oleh gangguan perkembangan motorik halus $(12,2 \%)$. Di usia 4 tahun anak sudah menguasai dasar-dasar perkembangan bahasa, namun 5\% sampai $8 \%$ dari anakanak mengalami keterlambatan bahasa atau kelainan pada masa prasekolah yang akan mengakibatkan gangguan belajar, sosio-emosional atau masalah perilaku sampai ia beranjak dewasa. Diperkirakan di usia 2 tahun 20\% anak mengalami gangguan bahasa dan 50\%-60\% terjadi di usia anak 4-5 tahun (Dewi, 2012),(Eun et al., 2014).

Stimulasi dan identifikasi awal anak-anak dengan masalah pertumbuhan dan perkembangan keluarga kerap keliru karena dipengaruhi oleh cara dalam keluarga (terutama ibu atau pengasuh) memberikan stimulasi dan mengenali dari penyimpangan dan memutuskan hasil dari pendeteksian tersebut. Penyimpangan perkembangan anak dapat dilakukan oleh ibu dengan membandingkan rekan-rekan mereka dari usia yang sama, ketika mereka mengunjungi klinik atau dokter anak dengan pengetahuan dasar tentang tumbuh kembang anak (Soetjiningsih P A, 2001).

Selain identifikasi dari gangguan pertumbuhan dan perkembangan berdasarkan penelitian sebelumnya, stimulasi juga sangat berperan pentig untuk meningkatkan pertumbuhan dan perkembangan anak (Walker SP, Wachs TD, Gardner JM, Lozoff B, Wasserman GA, Pollitt E, 2007).

Stimulasi merupakan kegiatan untuk merangsang kemampuan dasar anak sehingga tumbuh dan berkembang secara optimal. Setiap anak perlu mendapat stimulasi rutin sedini mungkin dan terus menerus di setiap kesempatan. Stimulasi dapat diberikan oleh orang-orang terdekat seperti halnya orangtua. Menurut hasil penelitian kurangnya stimulasi pada anak akan 
menyebabkan penyimpangan tumbuh kembang hingga gangguan yang menetap (Sulistyawati A., 2014).

Dalam pelaksanaan pemantauan atau deteksi dini tumbuh kembang peran tenaga kesehatan dalm hal ini adalah bidan sangat menentukan keberhasilan pencapaian cakupan deteksi dini dan stimulasi tumbuh kembang anak balita. Dalam melaksanakan perannya bidan bertanggung jawab tidak hanya melakukan deteksi dini secara langsung namun di tuntut untuk lebih mengoptimalkan kesadaran orang tua dalam pemantauan dan pemberian stimulasi tumbuh kembang pada anak sesuai usia sehingga keterlambatan dalam pencapaian tumbuh kembang dapat diminimalisasikan (Diana, 2004).

KPSP adalah kuisioner yang ditanyakan/dijalankan oleh orang tua/tenaga ahli untuk mengetahui apakah perkembangan anak tersebut normal dengan indikator yang telah ditetapkan. Namun, masih kurangnya sosialisasi tentang pentingnya KPSP mengakibatkan pengetahuan masyarakat tentang KPSP masih kurang. Kuesioner pra skrining perkembangan (KPSP) untuk membantu para tenaga kesehatan, kader dan terutama orang tua agar memiliki pemahaman yang benar dan cepat dalam mendiagnosa keterlambatan perkembangan balita (Suryanto, Purwandari H, 2014),(Faozan, 2014).

Tujuan dari kegiatan ini adalah untuk meningkatnya motivasi masyarakat khususnya ibu balita untuk melakukan pemeriksaan perkembangan anak secara rutin, meningkatnya partisipasi ibu balita untuk melakukan pemeriksaan perkembanagan anak menggunakan KPSP, Deteksi dini gangguan pertumbuhan dan perkembangan anak balita.

\section{METODE PELAKSANAAN}

Tempat dan waktu: Kegiatan deteksi perkembangan anak umur 3-72 bulan dilaksanakan pada tanggal 27 September 2019 di TK Alkhairat Labuan Desa Labuan Kecamatan Lage.

Khalayak sasaran: Khalayak sasaran dalam kegiatan ini adalah ibu yang memiliki anak 3 bulan -72 bulan. Ibu merupakan orang-orang yang memiliki interaksi atau kedekatan dengan anak atau balita secara intensif, sehingga diharapkan dapat melaksanakan pemantauan perkembangan dan deteksi dini penyimpangan perkembangan anak.

\section{Metode Pengabdian}

1. Ceramah bervariasi

Penggunaan metode ini dengan pertimbangan bahwa metode ceramah yang dikombinasikan dengan gambar-gambar, lembar balik dan display dapat memberikan materi yang relatif banyak secara padat, cepat dan mudah. Materi yang diberikan meliputi: konsep pertumbuhan dan perkembangan anak $3-72$ bulan dan cara menstimulasi perkembangan anak serta mengukur perkembangan dengan menggunakan kuisioner praskrining perkembangan.

2. Demonstrasi

Demonstrasi dilakukan oleh pemateri penyuluhan di hadapan ibu - ibu yang memiliki anak 3 bulan - 72 bulan. Masing - masing ibu ditanyakan usia anaknya dan melakukan deteksi dini tumbuh kembang menggunakan KPSP sesuai usia anak. Setelah selesai dilakukan DDTK pada anak 3 - 72 bulan, hasil deteksi disampaikan pada ibu anak serta memberikan nasehat /anjuran pada anak sesuai hasil yang diperoleh. 


\section{HASIL DAN PEMBAHASAN}

\section{A. Hasil}

Kegiatan deteksi perkembangan anak umur $3-72$ bulan dilaksanakan pada tanggal 27 September 2019 di TK Alkhairat Labuan Desa Labuan Kecamatan Lage.

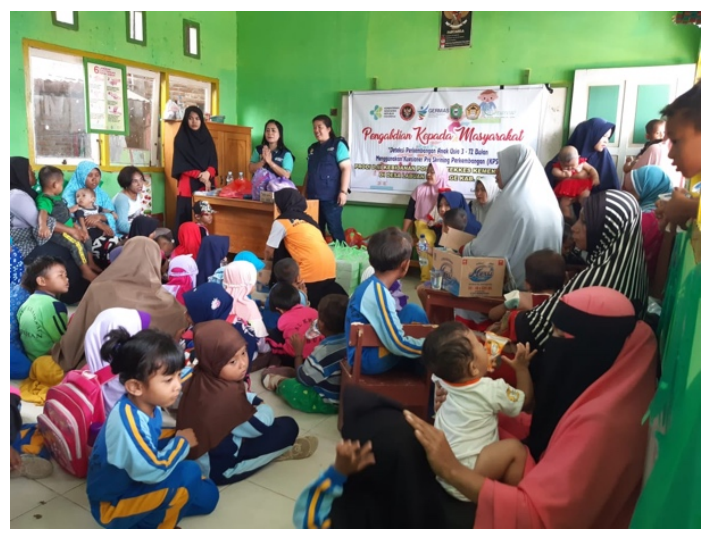

Gambar 1: Penyampaian materi penyuluhan

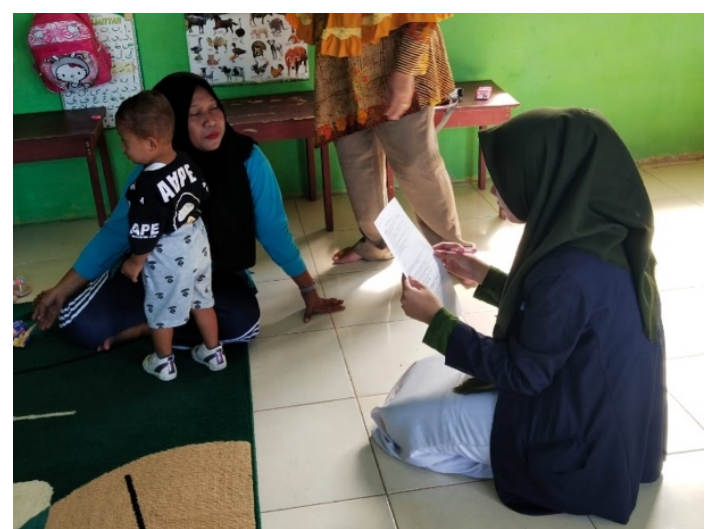

Gambar 2: pelaksanaan deteksi perkembangan

Hasil kegiatan deteksi perkembangan anak umur $3-72$ bulan sebagai berikut:

Tabel 1

Distribusi Hasil Skrining Perkembangan Anak Usia 3 - 72 Bulan di Desa Labuan Kecamatan Lage

\begin{tabular}{lcc}
\hline \multicolumn{1}{c}{ Umur } & Jumlah & Persentase (\%) \\
\hline Sesuai (S) & 134 & 95,7 \\
Meragukan (M) & 6 & 4,3 \\
Penyimpangan (P) & 0 & 0 \\
\hline & 140 & 100 \\
\hline
\end{tabular}

Berdasarkan tabel 1, dari 140 anak umur 3 - 72 bulan yang dilakukan deteksi perkembangan menggunakan Kuesioner Pra Skrining Perkembangan (KPSP) terdapat 134 anak $(95,7 \%)$ dengan hasil yang sesuai dan 6 orang $(4,3 \%)$ dengan hasil meragukan dan tidak ada $(0 \%)$ yang mengalami penyimpangan.

\section{B. Pembahasan}

Pada anak yang memperoleh hasil skrining sesuai, dilakukan intervensi : memberi pujian kepada ibu karena telah mengasuh anaknya dengan baik, menganjurkan ibu untuk meneruskan pola asuh anak sesuai dengan tahap perkembangan anak, memberi stimulasi perkembangan anak setiap saat, sesering mungkin, sesuai dengan umur dan kesiapan anak, serta mengikutkan anak pada kegiatan penimbangan dan pelayanan kesehatan di Posyandu secara teratur sebulan 1 kali dan setiap ada kegiatan Bina Keluarga Balita (BKB). Jika anak sudah memasuki usia prasekolah ( 36 - 72 bulan), anak dapat diikutkan pada kegiatan di Pusat Pendidikan Anak Usia Dini (PAUD), kelompok bermain dan Taman Kanak - Kanak, serta membawa anak untuk dilakukan pemeriksaan/ skrining rutin menggunakan KPSP setiap 3 bulan pada anak berumur kurang dari 24 bulan dan setiap 6 bulan pada anak umur $24-72$ bulan. 
Pada 6 anak yang diperoleh hasil skrining meragukan, dilakukan intervensi : memberi petunjuk pada ibu agar melakukan stimulasi perkembangan pada anak lebih sering lagi, setiap saat dan sesering mungkin, mengjarkan ibu cara melakukan intervensi stimulasi perkembangan anak untuk mengatasi penyimpangan/mengejar ketertinggalannya. Selain itu setelah 2 minggu kemudian, dilakukan penilaian ulang perkembangan anak. Hasil dari penilaian perkembangan setelah 2 minggu :

Tabel 2

Distribusi Hasil Skrining Perkembangan Anak Meragukan setelah 2 Minggu

\begin{tabular}{lcc}
\hline \multicolumn{1}{c}{ Umur } & Jumlah & Persentase (\%) \\
\hline Sesuai (S) & 6 & 100 \\
Meragukan (M) & 0 & 0 \\
Penyimpangan (P) & 0 & 0 \\
\hline
\end{tabular}

Sumber : Data Primer, 2019

Berdasarkan tabel 2, dari 6 anak dengan hasil skrining meragukan, setelah 2 minggu kemudian dilakukan skrining, memperoleh hasil perkembangan 100\% sesuai.

Hal ini sejalan dengan hasil penelitian Sulistyawati (2014), yang menyatakan bahwa kurangnya stimulasi pada anak akan menyebabkan penyimpangan tumbuh kembang hingga gangguan yang menetap. Setiap anak perlu mendapat stimulasi rutin sedini mungkin dan terus menerus di setiap kesempatan. Stimulasi dapat diberikan oleh orang-orang terdekat seperti halnya orangtua (Sulistyawati A., 2014).

Secara umum ada 2 faktor yang memengaruhi gangguan tumbuh kembang anak, faktor dalam (internal) seperti genetik dan faktor luar (eksternal) seperti lingkungan. Masalah eksternal dapat diatasi dengan memberikan gizi yang baik dan memberikan stimulasi sesering mungkin berdasarkan tahap usia anak. Berdasarkan beberapa penelitian menyimpulkan stimulasi yang diberikan di lingkungan anak dapat memengaruhi pertumbuhan dan perkembangan anak menjadi baik (Powell et al., 2014) (Kementerian Kesehatan R.I, 2013a).

Orang tua memiliki peran sangat penting khususnya ibu-ibu dalam mencegah keterlambatan pertumbuhan dan perkembangan anak mereka serta meningkatkan kualitas hidup anak mereka dimasa dewasa kelak. Penelitian sebelumnya menunjukkan bahwa ibu yang berpartisipasi dalam mendeteksi perkembangan anak mereka, akan memberikan efek jangka panjang pada anak-anak mereka (Chamidah, 2013), (Juneja M, Mohanty M, Jain R, 2012),(Shams B, Golshiri P, 2013).

Deteksi dini penting dilakukan untuk mengidentifikasi penyimpangan pertumbuhan dan perkembangan sehingga upaya untuk stimulasi dapat dilakukan lebih awal. Hasil penelitian menunjukkan bahwa stimulasi dini dengan melibatkan ibu memiliki efek positif terhadap perkembangan anak (Soetjiningsih P A, 2001).

\section{KESIMPULAN}

Berdasarkan hasil Deteksi Dini Perkembangan pada 140 anak berusia 3 - 72 bulan di Desa Labuan Kecamatan Lage, terdapat 134 anak (95,7\%) dengan hasil yang sesuai dan 6 orang $(4,3 \%)$ dengan hasil meragukan. Dari 6 anak dengan hasil skrining meragukan, setelah 2 minggu kemudian dilakukan skrining, memperoleh hasil perkembangan $100 \%$ sesuai. Kegiatan ini menyarankan agar deteksi dini perkembangan perlu dilakukan secara rutin pada anak $3-12$ bulan dengan menggunakan KPSP sesuai usia anak. Deteksi dini perkembangan 
dapat menemukan gangguan pertumbuhan dan perkembangan anak sehingga dapat dilakukan intervensi sedini mungkin.

\section{UCAPAN TERIMA KASIH}

Penulis mengucapkan terima kasih kepada Kepala Desa Labuan, Kepala TK Alkhairat Labuan yang telah mendukung kegiatan ini sehingga bisa berjalan dengan baik dan lancar.

\section{DAFTAR PUSTAKA}

Bustan, M. N. (2007). Epidemilologi Penyakit tidak Menular. PT Rineka Cipta.

Chamidah. (2013). Pertumbuhan dan Perkembangan Anak. Rineka Cipta.

Dewi, F. K. (2012). Efektifitas SDIDTK Terhadap Peningkatan Angka Penemuan Dini Gangguan Tumbuh Kembang pada Anak Usia Balita di Posyandu Teluk Wilayah Puskesmas Purwokerto Selatan.

Diana, F. M. (2004). Hubungan Pola Asuh dengan Status Gizi Kelurahan Pasar Ambacang Kota Padang Tahun 2004. 19-23.

Eun, J. J., Lee, H. J., \& Kim, J. K. (2014). Developmental profiles of preschool children with delayed language development. 57(8), 363-369.

Faozan, A. (2014). Rancang bangun aplikasi KPSP sebagai upaya pencegahan gangguan perkembangan anak berbasis android. STIMIK AMIKOM Yogyakarta.

Juneja M, Mohanty M , Jain R, R. S. (2012). Ages and Stages Questionnaire as a Screening Tool for Developmental Delay in Indian Children. Indian Pediatrics., 49 June 16.

Kementerian Kesehatan R.I. (2013a). Pedoman Pelaksanaan Stimulasi, Deteksi Dan Intervensi Dini Tumbuh Kembang Anak Ditingkat Pelayanan Kesehatan Dasar. Kementerian Kesehatan R.I.

Kementerian Kesehatan R.I. (2013b). Riset Kesehatan Dasar. Badan Penelitian Dan Pengembangan Kesehatan Kementerian Kesehatan RI.

Powell, C., Baker-Henningham, H., Walker, S., Gernay, J., \& Grantham-McGregor, S. (2014). Feasibility of integrating early stimulation into primary care for undernourished Jamaican children: Cluster randomised controlled trial. BMJ Open, 89(329), 1-4. https://doi.org/10.4135/9781483346342.n248

Pujiawati D. (2013). Hubungan pola asuh dan status gizi dengan perkembangan psikomotor anak usia 6-12 bulan (Survey di Desa Karangsembung Kecamatan Jamanis Kabupaten Tasikmalaya Tahun 2013). J Universitas Siliwangi.

Shams B, Golshiri P, N. A. (2013). The Evaluation of Mothers' Participation Project in Children's Growth and Development Process: Using the CIPP Evaluation Model. $J$ Educ Health Promot. Published Online 2013 Apr 30. Doi: 10.4103/22779531.112692PMCID: PMC3778559., 2(21).

Soetjiningsih P A. (2001). Role of Mother's Perceptions on Their Child Development on Early Detection of Developmental Deviation. Paediatrica Indonesiana, 41, 264-267.

Sulistyawati A. (2014). Deteksi Tumbuh Kembang Anak. Salemba Medika.

Suryanto, Purwandari H, M. W. (2014). Dukungn keluarga dan sosial dalam pertumbuhan dan perkembangan personal sosial, bahasa dan motorik pada balita di Kabupaten Banyumas. Jurnal Kesehatan Masyarakat, 10(1), 103-109.

Sutiari, N. K., \& Wulandari, D. A. R. (2011). Hubungan status gizi waktu lahir dengan pertumbuhan dan perkembangan anak usia pra sekolah di Desa Peguyangan, Kota Denpasar. Jurnal Ilmu Gizi, 2(2), 109-117. 
Uswaton, A., \& Wulandari, A. (2011). Hubungan lingkar kepala dengan perkembangan anak usia 12-24 bulan di Posyandu Tlogowatu Kemalang Klaten. Jurnal Involusio Kebidanan, 1(2), 37-44.

Walker SP, Wachs TD, Gardner JM, Lozoff B, Wasserman GA, Pollitt E, C. J. (2007). International Child Development Steering Group. Child development: Risk factors for adverse outcomes in developing countries. The lancet. 2007 Jan 19;369(9556):145-57. 369(9556), 145-157. 